\title{
Editorial
}

\section{Health Promotion Heroes}

The Canadian Journal of General Internal Medicine-your Journal-exists to promote scholarship in general internal medicine and to raise awareness of issues important in our practices. I am delighted to announce a new initiative in the Journal aimed at disseminating the work of the CSIM's Health Promotion Committee. This group is capably (and enthusiastically!) led by Dr. Bert Govig and aims to support health promotion activities by CSIM members and beyond. Each issue will showcase the activity of a Health Promotion (HP) Hero. The first to be recognized in our upcoming CJGIM issue is Dr. Thomas Brothers, who also holds the distinction of being the 2018 recipient of the CSIM's Hui Lee Health Promotion Scholarship.

Regaining a focus on health promotion is important because many of us were drawn to medicine to prevent disease and suffering. Our training, however, and the structure of the health care system focuses our attention on measurable biologic defects, leading most of us to remain busy diagnosing and treating patients with acute and chronic problems. Despite the realities of our daily practice, we need to find time (however little it may be) to seek an island of health promotion while navigating the sea of diagnosis, treatment and short-term crisis management.
Health promotion can have many faces. Twenty years ago, I codeveloped evidence-based guidelines for the prevention and treatment of obesity. At that time, we found little evidence to guide clinicians towards effective community-based prevention programs or towards prevention or treatment strategies for individuals. This was frustrating as our intuition was that population-based interventions like compulsory physical education from grades 1-12, made sense. As we know, lack of evidence is not the same as lack of effect, and in this case was possibly due to a lack of research funding. Health Promotion now is a priority for governments and health care systems everywhere, and emerging research is starting to address an increasing range of interventions addressing social determinants of health. We are excited about raising the profile of Health Promotion with this new feature of the Journal and look forward to being inspired and educated by our HP Heroes.
James Douketis, MD

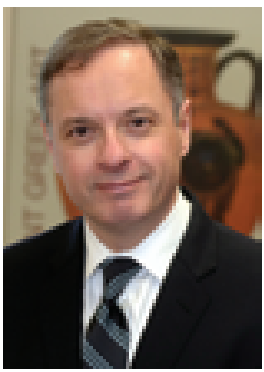

Editor-in-Chief 